\title{
Gravity Model: Reviewing The Potential of The Industry Commodity Export of Turkey to European Union
}

\author{
Ali Eren Alper*, Findık Özlem Alper ** \\ * Niğde Üniversitesi İktisadi ve İdari Bilimler Fakültesi Maliye Bölümü,Niğde Üniversitesi \\ İktisadi ve İdari Bilimler Fakültesi İktisat Bölümü \\ E-mail: alierenalper@gmail.com,ozknozlem@gmail.com \\ Copyright (C) 2015 Ali Eren Alper, Findik Özlem Alper. This is an open access article distributed \\ under the Eurasian Academy of Sciences License, which permits unrestricted use, distribution, \\ and reproduction in any medium, provided the original work is properly cited.
}

\begin{abstract}
At the second half of the 20th century, all of the world has witnessed a liberalization wave. The developing countries are influenced and adopted an export oriented industrialization program instead of an import oriented industrialization program. Export revenues, which are rising in recent years, are becoming one of the most important income resource of these countries. While portion of the export gains in the national income are increasing, export is getting a very substantial variable. However, world trade has experienced a tremendous transformation. Distance is still the main variable for describing this evolution, despite the presence of today's developed communication and transportation technologies. Gravity model is the most used method for observing the factors that affecting the external trade. As a result of the gravity model analysis, effect of the distance to Turkey's export is determining positive but too low. Main reasons of the positive coefficient is the rapid transition at the transportation and communication technologies and West European countries are being the fundamental markets of Turkey. Additioanlly, national incomes of the export markets, economic freedom in both Turkey and importing countries and population of Turkey is found statistically significant and positive. However, no effect is identifying of the export market population to Turkey's export.
\end{abstract}

Keywords: External Trade, Gravity Model, Industry Commodity Export, Panel Data Analysis, European Union

JEL-Clasification: F14, F15, F18

\section{Çekim Modeli: Türkiye’nin Avrupa Birliği’ne Sanayi Malı İhracat Potansiyelinin İncelenmesi}

\section{ÖZET}

20. yüzyılın ikinci yarısında tüm dünya liberalleşme dalgasına tanık olmuştur. Gelişmekte olan ülkeler bu akımdan etkilenmiş ve ekonomide ithal ikameci sanayileşme yerine ihracata dayalı büyüme politikasını benimsemiştir. Son yıllarda artan ihracat gelirleri bu ekonomilerin en önemli gelir kaynağı olmuştur. İhracat gelirlerinin milli gelir içindeki payı büyüdükçe, ihracat çok önemli bir değişken konumuna gelmiştir. Ancak dünya ticaretinin genel seyrinde büyük bir değişim vardır. Günümüzün gelişmiş iletişim ve ulaşım teknolojilerinin varlığına rağmen, bu değişimi açıklarken kullanılan temel değişken halen mesafedir. Dış ticarete etki eden faktörlerin incelenmesinde literatürde en çok kullanılan yöntem Çekim Modelidir (Gravity Model). Çekim modeli ile yapılan analiz sonucunda Türkiye'nin ihracatında, mesafenin etkisinin pozitif ancak 
çok küçük olduğu tespit edilmiştir. Pozitif katsayının temel sebebi de, ulaştırma ve bilişim teknolojisindeki hızlı gelişim ve Türkiye'nin AB'deki temel pazarlarının Batı Avrupa ülkeleri olmasıdır. Bunun dışında ihracat yapılan ülkelerin milli gelirleri, hem Türkiye hem de ithalatçı ülkelerdeki ekonomik özgürlük ve Türkiye'nin nüfusunun, ihracatına etkisinin anlamlı ve pozitif olduğu tespit edilmiştir. Ancak ihracat yapılan ülke nüfuslarının, Türkiye'nin ihracatına etkisi olmadığ

Anahtar Kelimeler: Dış Ticaret, Çekim Modeli, Sanayi Malı İhracatı, Panel Veri Analizi, Avrupa Birliği

\section{GİRIŞ}

1980’lerde az gelişmiş ülkelerin büyüme ve kalkınma politikaları Dünya Bankası ve Uluslararası Para Fonu (IMF) önerileri ile liberalleşme yönünde değişiklik geçirmiştir. Diğer birçok gelişmekte olan ülke gibi Türkiye de 24 Ocak 1980 Kararlarıyla birlikte ithal ikameci sanayileşme politikalarını terk ederek, dışa açık ihracata dayalı bir sanayileşme ve büyüme politikasını benimsemiştir. Makro açıdan incelendiğinde ihracat ülke ekonomileri açısından oldukça önem taşımaktadır. Çünkü ihracat performansı hem gelişmiş, hem de gelişmekte olan ülkelerde ekonomik gelişmişliğin temel göstergelerinden birisi olarak kabul edilmektedir.

Türkiye ile Avrupa Birliği (AB) arasındaki ticari ilişkiler 1963 yılında Ankara anlaşması ile başlamıştır. Bu anlaşmaya göre hazırlık, geçiş ve son dönem olmak üzere üç aşamalı bir süreç başlatılmıştır. Gümrük Birliği (GB) bu aşamaların son dönemidir. Türkiye'nin dış ticaret rakamları 1 Ocak 1996 tarihinde yürürlüğe konulan GB sonrasında yüksek seviyelere ulaşmıştır. Türkiye'nin AB (AB-28) ile olan dış ticaretine bakıldığında 2014 yılında AB'ye olan ihracat toplam ihracatın \%43,5'ini oluşturmaktadır. 2014 y1lı ithalat rakamlarına bakıldığında ise, AB'nin toplam ithalattan \%36,7 oranında pay aldığı görülmektedir (TÜİK). Bu oranlardan hareketle AB'yi Türkiye'nin en büyük ticaret ortağı olarak değerlendirmek mümkündür.

GB sonrası dönemde, Türkiye ihracatının kompozisyonunda dikkat çekici bir dönüşüm yaşandığı ve toplam ihracat gelirinde sanayi malları payı bakımından Türkiye'nin üst orta gelirli ülkeler ortalamasını aştığı görülmektedir. Özellikle, taşıt araçları ve madeni eşya ürünleri gibi katma değeri yüksek ve istihdam sağlayıcı sektörler ağırlık kazanmış ve rekabet gücünde de olumlu gelişmeler yaşanmıştır.

Bu çalışmanın temel amacı Türkiye'nin AB'ye olan sanayi malı ihracat potansiyelini çekim modeli (gravity model) yardımıyla incelemektir. İlk uygulamalarını Tinbergen (1962), Poyhonen (1963), Linnemann (1966)'nın yaptıkları ve Anderson (1979) ve Bergstrand (1985) tarafından sağlam teorik temellere oturtulan çekim modeli, günümüzde ikili ticaret akımlarının araştırılmasında başarı ile kullanılan bir analiz aracıdır. Bu modele göre, temel olarak iki ülke arasındaki ticaret, ülke milli gelirleri ile doğru orantılı olarak artmakta; ülkelerin aralarındaki mesafe arttıkça ise azalmaktadır.

Giriş bölümünün ardından, çalışmanın ikinci bölümünde çekim modelinin teorik altyapısı hakkında kısa bir bilgi verilmekte, üçüncü bölümde ise uluslararası ticaret akımlarının incelenmesinde çekim modelini kullanan literatürdeki çalışmalardan bahsedilmektedir. Dördüncü bölümde, çalışmada kullanılan çekim modeli, değişkenler ve veriler hakkında bilgi verilmektedir. Modelin tahmin sonuçlarının yer aldığı beşinci bölümü sonuç ve değerlendirme bölümü takip etmektedir.

\section{2. ÇEKIMM MODELI}

Dış ticaret akımlarını başarılı bir şekilde açıklayan çekim modelinin altyapısı fizik bilimindeki Newton'un çekim yasasına (Newton's law of gravitation) dayanmaktadır. Fizikte 
iki cisim arasındaki çekim kuvveti, cisimlerin büyüklükleriyle doğru orantılı, aralarındaki mesafenin karesiyle ters orantılıdır (Anderson, 2010:2). Benzer şekilde uluslararası ticarette kullanılan çekim modeli, iki ülke arasındaki ticaret hacmini söz konusu ülkelerin gayrisafi yurtiçi hasılalarına (GSYİH) ve bu iki ülke arasındaki mesafeye göre tahmin etmeyi amaçlar (Zhou, 2010:1629).

Uluslararası ticaret akımlarını açıklamada çekim modeli ilk olarak 1962 yılında J. Tinbergen tarafından kullanılmıştır. Tinbergen (1962), uluslararası ticari akımların ülkelerin ekonomik büyüklükleri yani GSYİH'ları ile pozitif ilişkili, ilgili ülkeler arasındaki fiziksel mesafe ile ters orantılı olduğunu gösteren ampirik bir çalışma yapmıştır. Buna göre, basit çekim modelini aşağıdaki formül yardımıyla göstermek mümkündür:

$$
\mathrm{F}_{\mathrm{ij}}=\mathrm{G} \frac{Y_{i} * Y_{j}}{D_{i j}}
$$

Eşitlikte yer alan F, i ülkesi ile j ülkesi arasındaki ticaret hacmini, $Y_{i}$ ve $Y_{j}$ sırasıyla $i$ ve $j$ ülkelerinin ekonomik büyüklüklerini (GSYİH ya da kişi başına GSYİH), $\mathrm{D}_{\mathrm{ij}}$ ülkelerin başkentleri veya ticaret merkezleri arasındaki mesafeyi, $G$ de yerçekimi sabitini göstermektedir/temsil etmektedir.

Eşitlik 1'in her iki tarafının logaritması alındığında model doğrusallaştırılmış olur:

$$
\ln \mathrm{F}_{\mathrm{ij}}=\log (\mathrm{G})+\log \left(\mathrm{Y}_{\mathrm{i}}\right)+\log \left(\mathrm{Y}_{\mathrm{j}}\right)-\log \left(\mathrm{D}_{\mathrm{ij}}\right)
$$

Eşitlik 2'ye göre iki ülke arasındaki ticaret hacmi, ülkelerin büyüklüklerinin artan, aralarındaki mesafenin ise azalan bir fonksiyonudur (Reinert, 2010:567-568).

Çekim modelinin ampirik olarak yüksek bir açıklama gücü sergilemesinin ardından bu konudaki çalışmalar artmış ve denkleme yeni değişkenler eklenerek (ortak dil, sınır paylaşımı, taşıma maliyetleri, serbest ticaret anlaşmaları, nüfus, kültürel ve politik faktörler, para birliklerini gösteren kukla değişkenler, vs.) modelin zenginleştirilmesi ve genişletilmesi üzerine yoğunlaşılmıştır (Tripathi, Carlos Leitão, 2013:3-4).

Her ne kadar teorik altyapısının yetersizliği başta olmak üzere çeşitli açılardan eleştirilse de $^{1}$, uluslararası ticaret akımlarını incelemede çekim modelini kullanmanın iki avantajı vardır. Bunlardan ilki, model için gerekli olan verilerin kolay bulunabilir ve güvenilir olması, ikincisi de uluslararası ticaret akımlarını araştırmada bu modellerin kullanımı için teorik düşüncelerin ayrıntılı biçimde tartışılmış ve geliştirilmiş olmasıdır (Paas, 2002:1).

\section{LITERATÜR}

Ülkeler arasındaki ticari akımların tahmini için başvurulan çekim modeli uygulamaları literatürde büyük ilgi çekmektedir. Bu çalışmalarda hem yatay kesit, hem de panel veriler kullanılmaktadır.

Nitsch (2000) AB içinde uluslararası ticaret üzerinde ulusal sınırların etkisini araştırmak için çekim modelini kullanmıştır. Yazar, 1979-1990 dönemini ve 12 AB ülkesini kapsayan panel veri setini kullanmış ve birlik içindeki uluslararası ticarette ulusal sınırların hala önemini koruduğu sonucuna ulaşmıştır.

Soloaga ve diğerleri (2001), 1980-1996 dönemi yatay kesit verilerini kullanarak 58 ülkeden oluşan bir örneklem içinde bölgeselciliğin ve ticaret anlaşmalarının etkisini incelemek amacıyla bir çekim modeli kullanmıştır. Çalışmada yeni bölgeselciliğin blok içi ticarete önemli bir etkisinin olmadığ 1 ve sadece $\mathrm{AB}$ ve Avrupa Serbest Ticaret Birliği (EFTA) için ticaret saptırıcı etkinin bulunduğu sonucuna ulaşılmıştır.

Fukao ve diğerleri (2003), çekim modelini kullanarak Amerika Serbest Ticaret Bölgesi Anlaşması (NAFTA)'nın ticaret yaratma ve ticaret saptırma etkilerini incelemiştir. Çalışmada, 1992-1998 dönemine ait NAFTA üyelerinin panel veri seti kullanılmıştır. Sabit etkili en küçük

\footnotetext{
${ }^{1}$ Bu konuda bkz: Bergstrand (1985), Porojan (2001), Filippini ve Molini (2003), Armstrong (2007).
} 
kareler yönteminin kullanıldığı çalışmada NAFTA için ticaret yaratıcı ve ticaret saptırıcı etkinin bulunduğu ileri sürülmüştür.

Sohn (2005), 1995 y1lı yatay kesit verilerini kullanarak Güney Kore ve otuz ticaret partneri arasındaki ticaret akımlarını analiz etmek için bir çekim modeline başvurmuştur. Ampirik sonuçlar, Güney Kore ticaret yapısının bir Heckscher-Ohlin modelini izlediğini ve Asya-Pasifik ticaret ağının Kore'nin ticaret hacmi üzerinde önemli pozitif etkiye sahip olduğunu göstermiştir.

Carrēre (2006), 130 ülkeyi kapsayan bir çekim modeli kullanarak bölgesel ticaret anlaşmalarının etkisini incelemiştir. Çalışmada 1962-1996 dönemini kapsayan panel veri seti kullanılmış ve bölgesel anlaşmaların üyeler arasındaki ticareti önemli ölçüde artırdığı bulunmuştur.

Bun ve diğerleri (2007), AB-15 ile Norveç, İsviçre, Kanada, Japonya ve ABD arasındaki ticarette Euro'nun etkisini araştırmak için bir çekim modeli kullanmışlardır. 1967-2002 dönemi panel veri setinin kullanıldığı çalışmada, Euro'nun benimsenmesinin söz konusu ülkeler arasındaki ticareti sadece $\% 3$ oranında arttırdığ sonucuna ulaşılmıştır.

Kepaptsoglou ve diğerleri (2009), çekim modelini kullanarak AB ile Akdeniz ülkeleri arasındaki serbest ticaret anlaşmalarının, ticaret üzerindeki etkilerini araştırmışlardır. Çalışmada 1993-2007 dönemi panel veri seti kullanılmış ve serbest ticaret anlaşmalarının ülkeler arasındaki ticaret akımlarını etkilediği fakat etkinin ulaşım maliyetleri gibi diğer faktörlerle karşılaştırıldığında oldukça düşük olduğu gözlenmiştir.

Sümer (2009) çekim modeli yardımıyla, 2006 yılında Türkiye'ye yatırım yapan 38 farklı ülkeden yatırımcıların yatay kesit verileri ile doğrudan yabancı yatırımları (DYY) incelemiştir. Genişletilmiş çekim modeli tahmin sonuçlarına göre, Türkiye'ye yatırım yapan yatırımcılar bağlı bulundukları ülkenin ekonomik büyüklügünden pozitif, uzaklığından ise negatif etkilenmektedirler.

Sousa (2011) gelişmiş ve gelişmekte olan 203 ülkenin verilerini kullanarak bir çekim modeli tahmin etmiş ve para birliğinin ticaret üzerindeki etkisinin zamanla azaldığı sonucuna ulaşmıştır.

Dilanchiev (2012), çekim modelini kullanarak Gürcistan'ın ticaret potansiyelini incelemiştir. 2000-2011 panel veri setinin kullandığı çalışmasında, GSYİH, kişi başına GSYİH ve doğrudan yabancı yatırımın ticareti olumlu etkilediğini tespit etmiştir.

Khan ve diğerleri (2013), 1990-2010 dönemi panel veri setini kullanarak oluşturdukları çekim modelinde Pakistan ile önemli ticaret ortakları arasındaki ticaret akımlarını incelemişlerdir. Yazarlar, GSYİH ve kişi başına GSYİH'nın ticaret hacmini pozitif olarak etkilediği, mesafe ve kültürel benzerliklerin ise negatif olarak etkilediği sonucuna ulaşmışlardır.

Iwasaki ve diğerleri (2013) çekim modelini kullanarak Rusya'nın ticaret hacminde hangi faktörlerinin belirleyici olduğunu araştırmıştır. Rusya ve OECD üyesi 23 ülkenin 19952011 dönemine ait panel veri setinin kullanıldığı çalışmanın tahmin sonuçları doğrudan yabancı yatırım ve sosyo-kültürel benzerliğin Rusya ve söz konusu gelişmiş ülkeler arasındaki ticaret hacminde belirleyici faktörler olduğunu göstermiştir.

Elshehawy ve diğerleri (2014) Mısır'ın ihracatını belirleyen faktörleri araştırmak için bir çekim modeli kullanmıştır. Mısır'ın ve 42 ticaret partnerinin 2000- 2013 dönemi panel veri setinin kullanıldığı çalışmada, ülkelerin GSYİH'nın, ithalatçı ülkenin nüfusunun, bölgesel ticaret anlaşmalarının ve ülkeler arasındaki sınırın Mısır'ın ihracatını pozitif yönde etkilediği sonucuna ulaşılmıştır.

Genç ve diğerleri (2014) Yeni Zelanda'nın ticaretinde engellerin rolünü araştırmak için Yeni Zelanda ve 200 ticaret partnerinin 2001-2006 dönemi verilerini kullanarak bir çekim modeli tahmin etmiştir. Sonuçlar özellikle ticaret politikası dışındaki politikalarla ilgili olan 
engellerin (mülkiyet hakları, yolsuzluk, vs.) ticaret hacmini önemli ölçüde etkilediğini göstermiştir.

Prasai (2014) Nepal ve 94 ticaret partnerinin 1981-2009 dönemi panel veri setinden oluşan bir çekim modeli kullanarak Nepal'in ticaret yapısını incelemiştir. Ampirik sonuçlar, GSYİH'nın ticaret hacmini pozitif olarak, mesafenin ise negatif olarak etkilediğini ve ekonomik liberalizasyon sonrası Nepal'in ticaret hacminde önemli bir yapısal kırılmanın olmadığını göstermiştir. Çalışmada ayrıca ticaretten fayda sağlamak için Nepal'in Çin ile bir ticaret anlaşması yapması gerektiği sonucuna ulaşılmıştır.

Tabari ve diğerleri (2014) çekim modelini kullanarak İran'ın ticareti ile bölgesel ticaret ve reel döviz kuru arasındaki ilişkiyi analiz etmiştir. İran ve 45 Asya ülkesinin 2001-2011 dönemi panel veri setinin kullanıldı ğı çalışmada bölgesel ticaretin İran'ın dış ticaretini arttırdığ ve Rial'in reel döviz kurundaki bir yükselmenin ticaret dengesizliğini azalttığı ileri sürülmüştür.

Son yıllarda çekim modeli kullanılarak Türkiye'nin dış ticaret akımlarının analiz edildiği çalışmaların sayısında bir artış gözlenmektedir. Antonucci ve Manzocchi (2006), 19672001 dönemi panel veri setini kullanarak oluşturdukları çekim modelinde "modelin Türkiye'nin ticaret özelliklerine uygun olup olmadığ 1 ve Türkiye'nin AB ile özel bir ticari ilişkisi var mı?" sorularına cevap aramışlardır. Çalışmadan elde edilen sonuçlar, çekim modelinin Türkiye'nin ticaret özelliklerine uygun olduğunu ancak, Türkiye ile AB arasında özel bir ticari ilişkinin olmadığını göstermiştir.

Nowak-Lehmann ve diğerleri (2007), Türkiye'nin AB'ye olan ticaret akımlarında GB'nin etkisini incelemek amacıyla bir genel çekim modeli kullanmışlardır. 1988-2002 dönemi panel veri setinin kullanıldığı çalışmada, GB sonrasında Türkiye'nin AB'ye olan ihracatının $\operatorname{arttığ1~sonucuna~varılmıştır.~}$

Karagöz ve diğerleri (2009), 2005 yılında Türkiye ile dış ticaret ilişkisinde bulunan 169 ülkeye ait yatay kesit verilerine dayalı genişletilmiş çekim modelini kullanarak Türkiye'nin küresel ticareti üzerinde hangi faktörlerin etkili olduklarını ve hangi ülkelerle ticaretin potansiyel genişleme vaat ettiğini araştırmışlardır. Modelin tahmin sonuçlarına göre, Türkiye'nin dış ticareti ticaret yapılan ülkenin ekonomik büyüklüğünden, Türkiye'ye tarihsel ve kültürel yakınlık içinde olmasından ve İslam ülkesi olmasından olumlu, nüfus büyüklügü ve aradaki mesafeden olumsuz yönde etkilenmektedir.

Tatlıcı ve diğerleri (2011), 46 ülkenin 1994-2007 dönemi panel veri setinin kullanıldığı bir çekim modelinde Türkiye'nin ihracat potansiyelini araştırmışlardır. Ampirik sonuçlar, Türkiye'nin ihracatında mesafenin, Türkiye'nin milli gelirinin ve Türkiye'nin ihracat yaptığ ülkelerin milli gelirlerinin etkili olduğunu; ülkelerin nüfuslarının, GB anlaşmasının ve ülkelerle ortak sınırı paylaşmanın ise anlamlı bir etkiye sahip olmadığını göstermiştir.

Özkaya (2011), 1996-2006 dönemi panel veri seti ile oluşturduğu genel çekim modelinde, Türkiye'nin taraf olduğu ikili ve çok taraflı ekonomik ve ticari anlaşmaların Türkiye'nin 113 ülkeye yaptığı ihracat üzerinde etkisi olup olmadığını araştırmıştır. Özkaya, imzalanan ikili anlaşmaların Türkiye'nin ihracatı üzerinde istatistiksel olarak anlamlı bir etkisinin olmadığı ve GB hariç diğer çok taraflı anlaşmaların Türkiye'nin ihracatı üzerinde istatistiksel olarak anlamlı pozitif etkisi olduğu sonucuna varmıştır.

Atabay Baytar (2012), Türkiye ve BRIC ülkeleri (Brezilya, Rusya, Hindistan, Çin) arasındaki ticaret hacminin belirleyicilerini çekim modeli ile analiz etmiştir. 2001-2010 dönemi panel veri setinin kullanıldığı çalışmada, Türkiye'nin BRIC ülkeleriyle olan dış ticaretinde ülkelerin GSYİH'larının, nüfuslarının ve aralarındaki mesafenin anlamsız olduğu, ithalat ve ihracat değişkenlerinin ise anlamlı ve ticaret hacmini arttırıcı etkide bulunduğu sonucuna ulaşılmıştır.

Sandalcılar (2012) 2002-2009 dönemine ait yıllık verileri kullanarak Türkiye ile BRIC ülkeleri arasındaki dış ticaret hacminin belirleyicilerini tahmin etmiştir. Panel çekim modelinin 
kullanıldığ nüfusları ve ortak sınıra sahip olmaları pozitif olarak, ülkeler arasındaki mesafenin ise negatif olarak etkilediği tespit edilmiştir. Çalışmada ayrıca Türkiye'nin Brezilya, Hindistan ve Çin ile ticari potansiyelinin altında, Rusya ile ticari potansiyelinin üzerinde bir ticaret gerçekleştirdiği sonucuna ulaşılmıştır.

Doğan ve diğerleri (2015) 1995-2014 dönemine ait panel veri setinden oluşan bir çekim modeli kullanarak Türkiye'nin Afrika ülkeleri ile olan ticareti üzerinde hangi faktörlerin etkili olduğunu araştırmıştır. Yazarlar, ticaret yapılan ülkenin GSYİH'nın ticaret hacmi üzerinde pozitif etkisinin olduğu, Türkiye ile ticaret yapacak ülke arasındaki mesafenin ve vize uygulamasının ticaretin büyüklüğünü belirlemede anlamlı bir etkisinin olmadığı sonucuna ulaşmıştır.

\section{MODEL VE DEĞİSTKENLER}

$\mathrm{Bu}$ çalışmada, çekim modeli Türkiye'nin AB'ye sanayi malları ihracatı üzerine uygulanmıştır. Modelde temel çekim denkleminden yararlanılmaktadır. Bunun için Türkiye'nin en çok ihracat yaptığ 14 AB üyesi ülke (Fransa, Hollanda, Almanya, İtalya, İngiltere, Danimarka, Yunanistan, Portekiz, İspanya, İsveç, Avusturya, Polonya, Çek Cumhuriyeti ve Romanya) ve 2002-2012 yılları arasını kapsayan panel veri kullanılmaktadır.

Temel çekim denkleminde bağımlı değişken olarak Türkiye'nin ihracatı alınmaktadır. Açıklayıcı değişkenler olarak da partner ülkelerin reel gayri safi yurt içi hasılaları (GSYİH), başkentlerinin Ankara'ya olan mesafeleri, Türkiye'nin ve partner ülkelerin nüfusları ve ekonomik özgürlük indeksleri modele dahil edilmektedir.

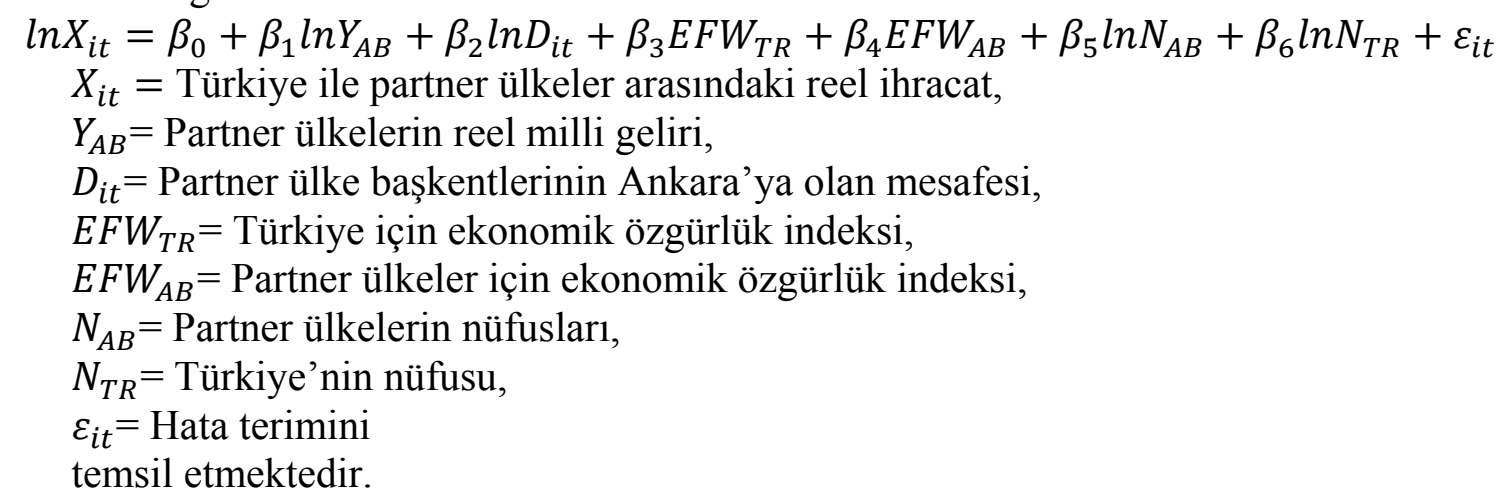

Modeldeki ülkeler Türkiye'nin AB'ne 2011 ve 2012 yıllarında yaptığı sanayi malları ihracatının \% 90'lık kısmını açıklama gücüne sahiptir. Analizde bağımlı değişken olarak alınan ihracat verisi Türkiye İstatistik Kurumu'ndan (TUIK) elde edilmiştir. Partner ülkelerin reel milli geliri, Türkiye'nin ve partner ülkelerin nüfusları Eurostat veri tabanından elde edilmiştir. Ülkelerin başkentlerinin Ankara'ya uzaklıklarını gösteren mesafe verilerine "European Comission Distance Calculator" veri tabanından ulaşılmıştır. Ekonomik özgürlük indeksine ise, Fraser Enstitüsü 2014 Yı1lık Ekonomik Özgürlük Raporu" ndan elde edilmiştir. Modelin tahmininde Stata 13 ekonometrik programından yararlanılmıştır.

\section{UYGULAMA}

Panel veri regresyon modelleri, birimler arasında yatay kesit bağımsızlığı varsayımına dayanmakta olup, Baltagi (2005) panel veri analizinde uzun dönemde serilerde rastlanacak yatay kesit bağımlılığının standart sabit etki (FE) ve rassal etki (RE) tahminlerinin tutarlı ancak etkin olmamalarına ve tahmin edilen standart hataların sapmalı olmasına neden olduğunu belirtmiştir. Bu nedenle panel veri analizlerinde yatay kesit bağımlılığını test eden birkaç farklı test kullanılmaktadır. Çalışmada bu testlerden birimler arasında korelasyonun varlığına bakan 
Pesaran (2004) testi ve Spearman'ın rank korelasyon katsayısını kullanarak ortalama değer hesaplayan ve parametrik olmayan Friedman (1937) testi kullanılmış olup, sonuçlara aşağıdaki tabloda yer verilmiştir.

\begin{tabular}{lll}
\hline Test & İstatistik Değeri & Olasılık \\
\hline Pesaran Testi & 4.459 & 0.000 \\
\hline Friedman Testi & & \\
\hline
\end{tabular}

\section{Tablo-1: Yatay Kesit Bağımlılığı Test Sonuçları}

Her iki testte yatay kesit bağımlılı̆̆ını (CSD) tespit etmektedir. Bu tespitin bizim için önemi, panel regresyon tahminini yaparken kullanılacak tahmincinin yatay kesit bağımlılığını dikkate alan bir yöntem olması gerekliliğidir. Bu amaçla çalışmada CSD'yi dikkate alan Uygun Genelleştirilmiş En Küçük Kareler Yönteminin (Feasible Generalized Least Squares - FGLS) kullanılması uygun görülmüştür.

Panel regresyon tahmin sonuçları, aşağıda bir tablo halinde sunulmaktadır:

\begin{tabular}{|l|l|}
\hline Değişken & FGLS Tahmin Sonuçları \\
\hline $\mathrm{C}$ & $-0.326(0.093)^{2}$ \\
\hline$Y_{A B}$ & $2.978(0.165)$ \\
\hline$D_{i t}$ & $0.044(0.012)$ \\
\hline$E F W_{T R}$ & $0.330(0.142)$ \\
\hline$E F W_{A B}$ & $1.376(0.143)$ \\
\hline$N_{A B}$ & $0.493(1.059)$ \\
\hline$N_{T R}$ & $0.930(0.285)$ \\
\hline
\end{tabular}

\section{Tablo-2: Panel Regresyon Test Sonuçları}

Tablo 2'de de görüldüğü gibi, Türkiye'nin ihracat yaptığı AB ülkelerinin milli gelirlerini temsil eden $Y_{A B}$ değişkeninin katsayısı, istatistiki açıdan anlamlı ve pozitif işarete sahiptir. Bu sonuç çekim modelinin teorisi ile örtüşmektedir. Tahmin edilen modelde, Türkiye ihracatçı ülke; diğer ülkeler ise ithalatçı ülke konumundadır. İthalatçı ülkelerin milli gelirleri, o ülkelerin satın alma gücünü ifade etmektedir ve milli gelirlerinin artması bu ülkelere daha çok ithalat yapma imkanı vermektedir.

Çekim modelinin tahmin sonuçlarında partner ülkelerin başkentlerinin Ankara’ya olan mesafesini temsil eden $D_{i t}$ değişkeninin katsayısı istatistiki açıdan anlamlı, pozitif ancak çok küçük bulunmuştur. Bu Türkiye'nin AB'ye yaptığı sanayi malı ihracatında mesafenin artık çok önemli olmadığını göstermektedir. Lendle ve diğerleri (2013)'de de belirtildiği üzere mesafenin etkisi, özellikle de internet üzerinden yapılan alışverişlere bağlı olarak, \%65 oranında azalmıştır. Buna ek olarak Türkiye'nin AB içerisinde temel pazarlarının Batı Avrupa ülkeleri

\footnotetext{
2 Parantez içindeki değerler standart hataları göstermektedir.
} 
olduğunu düşünürsek, uzaklık katsayısının Türkiye'nin AB'ye sanayi malı ihracatını olumsuz yönde etkilemediğini görmekteyiz.

Türkiye'nin ve ihracat yaptığı $14 \mathrm{AB}$ ülkesinin ekonomik özgürlük indekslerini temsil eden, sırasıyla $E F W_{T R}$ ve $E F W_{A B}$ değişkenlerinin katsayılarının istatistiki açıdan anlamlı ve beklentiler doğrultusunda pozitif olduğu tespit edilmiştir. Dolayısıyla hem ihracatçı hem de ithalatçı pazarlardaki ekonomik özgürlük arttıkça, dış ticaret büyümektedir.

Türkiye'nin ihracat yaptığı AB ülkelerinin nüfuslarını temsil eden $N_{A B}$ değişkeninin katsayısı pozitif ve istatistiki açıdan anlamsız bulunmuştur. Ancak katsayısının anlamsız olmasından dolayı, ithalatçı ülkelerin nüfuslarının Türkiye'nin ihracatını etkilemediği tespit edilmiştir.

Türkiye'nin nüfusunu temsil eden $N_{T R}$ değişkenin katsayısı istatistiki açıdan anlamlı ve pozitif bulunmuştur. Çekim modellerinde nüfus genellikle ülke büyüklüğünü temsil etmek için kullanılır. Daha büyük nüfuslu ülkelerin daha fazla doğal kaynakla donatıldığı varsayılır. Dolayısıyla da bu ülkelerin üretim potansiyelleri daha yüksektir. Ayrıca, daha büyük bir nüfus daha büyük bir iç piyasaya sahiptir. Büyük bir iç piyasa ise emeğin bölünmesine ve bu yüzden çeşitli ürünlerin ticareti için fırsatlar yaratır (Tatlıcı ve Kızıltan, 2011: 296).

\section{SONUÇ}

$\mathrm{Bu}$ çalışmada çekim modeli, Türkiye'nin AB'ye sanayi malı ihracatını üzerine uygulanmış ve panel veri metodolojisi kullanılarak, değişkenlerin katsayıları tahmin edilmiş ve yorumlanmıştır. Modelde, 2002-2012 yılları arasını kapsayan verilerle, Türkiye'nin AB'ye yaptığı sanayi malı ihracatının, 2011 ve 2012 yıllarında \%90'lık kısmını açıklama gücüne sahip, $14 \mathrm{AB}$ üyesi ülke seçilmiştir.

Sonuç olarak Türkiye'nin ihracatında, mesafenin etkisinin pozitif ancak çok küçük olduğu tespit edilmiştir. Pozitif katsayının temel sebebi de, ulaştırma ve bilişim teknolojisindeki hızlı gelişim ve Türkiye'nin AB'deki temel pazarlarının Batı Avrupa ülkeleri olmasıdır. Bunun dışında ayrıca, ihracat yapılan ülkelerin milli gelirleri, hem Türkiye hem de ithalatçı ülkelerdeki ekonomik özgürlük ve Türkiye'nin nüfusunun, ihracatına etkisinin anlamlı ve pozitif olduğu tespit edilmiştir. Ancak ihracat yapılan ülke nüfuslarının, Türkiye'nin ihracatına etkisi olmadığ belirlenmiştir.

\section{REFERENCES}

- AKSOY, G. (2011). Arhavi (Artvin) ve Çevresinin Heyelan Duyarlılık Analizi, Yayımlanmamış Yüksek Lisans Tezi, Trabzon: Karadeniz Teknik Üniversitesi Fen Bilimleri Enstitüsü.

- Anderson, J.E. (1979). A theoretical foundation for the gravity equation. The American Economic Review, 69(1), 106-116.

- Anderson, J.E. (2010). The gravity model. NBER Working Paper Series, 16576, 1-45.

- Antonucci, D., \& Manzocchi, S. (2006). Does Turkey have a special trade relation with the EU? A gravity model approach. Economic Systems, 30, 157-169.

- Armstrong, S. (2007). Measuring trade and trade potential: A survey. Asia Pacific Economic Papers, 368, 1-17.

- Atabay-Baytar, R. (2012). Türkiye ve BRIC ülkeleri arasındaki ticaret hacminin belirleyicileri: Panel çekim modeli analizi. İstanbul Ticaret Üniversitesi Sosyal Bilimler Dergisi, 11(21), 403-424. 
- Baltagi, B. H. (2005). Econometric analysis of panel data. Chichester: John Wiley \& Sons Ltd.

- Bergstrand, J.H. (1985). The gravity equation in international trade: Some microeconomic foundations and empirical evidence. The Review of Economics and Statistics, 67(3), 474481.

- Bun, M.J., \& Klaassen, F.J. (2007). The Euro effect on trade is not as large as commonly thought. Oxford Bulletin of Economics and Statistics, 69(4), 473-496.

- Carrēre, C. (2006). Revisiting the effects of regional trade agreements on trade flows with proper specification of the garvity model. European Economic Review, 50, 223-247.

- Dilanchiev, A. (2012). Empirical analysis of Georgian trade pattern: Gravity model. Journal of Social Sciences, 1(1), 75-78.

- Doğan, B.B., \& Tunç, Ş.Ö. (2015). Türkiye'nin Afrika ülkeleri ile olan diş ticaretinin belirleyicileri: Panel çekim modeli yaklaşımı. Akademik Araştırmalar ve Çalışmalar Dergisi, 7(12), 1-17.

- Elshehawy, M.A., Shen, H., \& Ahmed, R.A. (2014). The factors affecting Egypt's exports: Evidence from the gravity model analysis. Open Journal of Social Sciences, 2, 138-148.

- Filippini, C., \& Molini, V. (2003). The determinants of East-Asian trade flows: A gravity equation approach. Journal of Asian Economics, 14, 695-711.

- Friedman, M. (1937). The use of ranks to avoid the assumption of normality implicit in the analysis of variance. Journal of the American Statistical Association, 32, 675-701.

- Fukao, K., Okubo, T., \& Stern, R.M. (2003). An econometric analysis of trade diversion under NAFTA. North American Journal of Economics and Finance, 14, 3-24.

- Genç, M., \& Law, D. (2014). A gravity model of barriers to trade in New Zealand. New Zealand Treasury Working Paper, 14/05, 1-55.

- Gwartney, J., Lawson, R. \& Hall, J. (2014). Economic Freedom of The World: 2014 Annual Report, Fraser Institute.

- Iwasaki, I., \& Suganuma, K. (2013). A gravity model of Russian trade: The role of foreign direct investment and socio-cultural similarity. RRC Working Paper, 40, 1-15.

- Karagöz, K., ve Karagöz, M. (2009). Türkiye'nin küresel ticaret potansiyeli: Çekim modeli yaklaşımı. C.Ü. İktisadi ve İdari Bilimler Dergisi, 10(2), 127-144.

- Kepaptsoglou, K., Tsamboulos, D.A., Karlaftis, M.G., \& Marzano, V. (2009). Free trade agreement effects in the Mediterranean region: An analytic approach based on SURE gravity model. Journal of the Transportation Research Board, 2097, 88-96.

- Khan, S., Haq, I., \& Khan, D. (2013). An empirical analysis of Pakistan's bilateral trade: A gravity model approach. The Romanian Economic Journal, XVI(48), 103-120.

- Lendle, A., Olarreaga, M., Schropp, S., \& Vézina, P. (2013). There goes gravity: How Ebay reduces trade costs?. CEPR Discussion Papers, No. 9094, 1-38.

- Linnemann, H. (1966). An econometric study of international trade flows. North Holland. Amsterdam.

- Nitsch, V. (2000). National borders and international trade: Evidence from the European Union. The Canadian Journal of Economics, 33(4), 1091-1105.

- Nowak-Lehmann, F., Herzer, D., Martinez-Zarzosu, I., \& Vollmer, S. (2007). The impact of a customs union between Turkey and the EU on Turkey's exports to the EU. JCMS Working Paper, 45(3), 719-743.

- Özkaya, H. (2011). İkili ve çok taraflı anlaşmaların Türkiye'nin ihracatı üzerindeki etkisi. Doğuş Üniversitesi Dergisi, 12(2), 279-288. 
- Paas, T. (2002). European integration and eastward enlargement process in international trade: Using a gravity approach for exploring bilateral trade flows. The 42nd Congress of the European Regional Science Association, Dortmund, Germeny, 1-18.

- Prasai, L.P. (2014). Foreign trade pattern of Nepal: Gravity model approach. NRB Working Paper, 21, 1-19.

- Poyhonen, P. (1963). A tentaive model for the volume of trade between countries. Weltwirtschatftliches. 90, 93-100.

- Porojan, A. (2001). Trade flows and spatial effects: The gravity model revisited. Open Economies Review, 12, 265-280.

- Pesaran, M.H. (2004). General diagnostic tests for cross section dependence in panels. Cambridge Working Papers in Economics, No. 0435.

- Reinert, K.A. (2010). Gravity models. In R.S. Rajan, K.A. Reinert, L.S. Davis \& A.J. Glass (Eds.), The Princeton encyclopedia of the world economy, 567-570. The Princeton University Press.

- Sandalcılar, A.R. (2012). Türkiye'nin BRIC ülkeleriyle ticari potansiyeli: Panel çekim modeli yaklaşımı. Journal of Yasar University, 25(7), 4164-4175.

- Sohn, C.H. (2005). Does the gravity model explain South Korea's trade flows?. The Japanese Economic Review, 56(4), 417-430.

- Soloaga, I., \& Winter, L.A. (2001). Regionalism in the nineties: What effect on trade? North American Journal of Economics and Finance, 12, 1-29.

- Sousa, J.D. (2011). The currency union effect on trade is decreasing over time. MPRA Working Paper, 35448, 1-43.

- Sümer, K.K. (2009). AB sürecinde diş ticaret modelleme tekniklerinde ekonometrik yaklaşımlar. Dilek Ofset Matbaacılık, İstanbul.

- Tabari, N.A.Y., \& Haghighat, S. (2014). Iran's regional trade and real exchange rate: Gravity panel data models. International Journal of Economy, Management and Social Sciences, 3(1), 113-117.

- Tatlıcı, Ö., ve Kızıltan, A. (2011). Çekim modeli: Türkiye'nin ihracatı üzerine bir uygulama. Atatürk Ü. İIBF Dergisi, 10. Ekonometrik ve İstatistik Sempozyumu Özel Sayıs1, 287-299.

- Tinbergen, J. (1962). Shaping the world economy: Suggestions for an international economic policy. Twentieth century fund. New York.

- Tripathi, S., \& Carlos Leitão, N. (2013). India's trade and gravity model: A static and dynamic panel data. MPRA Paper, 45502, 1-13.

- Zhou, M. (2010). Multidimensionality and gravity in global trade. Social Forces, 88(4), 1619-1643.

\section{INTERNET REFERENCES}

- www.tuik.gov.tr, (s.e.t: 29.04.2015).

- http://ec.europa.eu/eurostat/data/database, (s.e.t: 06.05.2015).

- http://ec.europa.eu/programmes/erasmus-plus/tools/distance_en.htm, (s.e.t: 28.03.2015). 